\title{
Circadian Phase-Dependent Modulation of cGMP-Gated Channels of Cone Photoreceptors by Dopamine and D2 Agonist
}

\author{
Gladys Y.-P. Ko, Michael L. Ko, and Stuart E. Dryer \\ Department of Biology and Biochemistry and Biological Clocks Program, University of Houston, Houston, Texas 77204-5001
}

The affinity of cGMP-gated ion channels (CNGCs) for cGMP in chick retinal cone photoreceptors is under circadian control. Here we report that dopamine (DA) and D2 receptor agonists evoke phase-dependent shifts in the affinity of CNGCs for activating ligand. Inside-out patch recordings from cultured chick cones were performed at circadian time (CT) 4-7 and CT 16-19 on the second day of constant darkness. Exposing intact cells to DA or the D2 agonist quinpirole for $2 \mathrm{hr}$ before patch excision caused a significant increase in the $K_{\mathrm{D}}$ for cGMP during the night (CT 16-19) but had no effect during the day (CT 4-7). DA or quinpirole treatment had no effect on the Hill slope or the average number of channels per patch. The effect of DA was blocked by the D2 antagonist eticlopride and was not mimicked by $\mathrm{D} 1$ agonists or blocked by $\mathrm{D} 1$ antagonists. By contrast, a brief $(15 \mathrm{~min})$ exposure to DA or quinpirole caused a decrease in $K_{\mathrm{D}}$ during the subjective day and had no effect during the subjective night. Thus, the effect of $\mathrm{D} 2$ agonists depends on both the duration of agonist exposure and the time of day. Application of DA or quinpirole evoked a transient activation of the MAP kinase Erk (extracellular signal-related kinase) during the day but caused a sustained inhibition during the night. Conversely, D2 agonists caused activation of $\mathrm{Ca}^{2+} /$ calmodulin-dependent protein kinase II during the night and inhibited this enzyme during the day. A circadian oscillator in cones appears to regulate the nature of the transduction cascade used by D2 receptors.

Key words: CNG channels; photoreceptor; cone; dopamine; circadian rhythm; D2 receptor

\section{Introduction}

Ambient light intensity varies by several orders of magnitude over the course of a day. Nevertheless, visual systems detect contrasts in the face of these large changes in illumination. Part of this capability can be attributed to background and bleaching adaptation, which occur in response to changes in illumination over time scales of seconds to minutes (Fain et al., 2001). Circadian oscillators provide an additional layer of control that allows visual systems to anticipate changes in illumination and modulate sensitivity over the course of a day (for review, see Cahill and Besharse, 1995).

Circadian control of retinal photosensitivity is associated with several rhythmic changes in the structure and physiology of the retina (Cahill and Besharse, 1995). Circadian rhythms can occur in retinal photoreceptors cultured in the absence of other functional cell types (Cahill and Besharse, 1993; Ko et al., 2001), indicating that circadian clocks are located within the photoreceptors themselves. Nevertheless, multiple cell types contribute to overall circadian control of the intact retina. Thus, melatonin secretion from photoreceptors is greater during the circadian night and results in several "dark-adaptive" effects in the inner retina and pigment epithelium (Cahill and Besharse, 1995).

Melatonin does not produce autocrine effects on avian photoreceptors but instead inhibits the secretion of dopamine (DA)

\footnotetext{
Received Dec. 13, 2002; revised Jan. 24, 2003; accepted Jan. 24, 2003.

This work was supported by National Institutes of Health (NIH) Grant EY-11973 to S.E.D. and NIH postdoctoral fellowship EY-13920 to G.K.

Correspondence should be addressed to Dr. Stuart E. Dryer, Department of Biology and Biochemistry, University of Houston, Houston, TX 77204-5513. E-mail: sdryer@uh.edu.

Copyright $\odot 2003$ Society for Neuroscience $\quad 0270-6474 / 03 / 233145-09 \$ 15.00 / 0$
}

from subpopulations of amacrine or interplexiform cells of the inner retina (Nowak et al., 1992). Consequently, retinal melatonin and DA are in antiphase during the circadian cycle and after application of brief light pulses (Adachi et al., 1998). DA can induce light-like phase shifts of photoreceptor circadian oscillators (Cahill and Besharse, 1991; Steenhard and Besharse, 2000) and contributes to circadian rhythms of rod-cone dominance (Witkovsky et al., 1988; Wang and Mangel, 1996; Manglapus et al., 1998, 1999). DA therefore functions as a feedback signal from the inner retina that refines and modulates circadian control mechanisms within the photoreceptors. In addition, DA produces several other light adaptive effects in the retina that are independent of its effects on circadian oscillators (Besharse and Iuvone, 1992; Cahill and Besharse, 1995). D2-type DA receptors are expressed in the outer and inner segments of many vertebrates, including chick (Burnside et al., 1993; Wagner et al., 1993; Hillman et al., 1995), and therefore it is possible that this neurohormone could affect phototransduction cascades directly.

Phototransduction in rods and cones is mediated by a G-protein-coupled cascade that culminates in the closure of cGMP-gated cationic channels (for review, see Burns and Baylor, 2001). Changes in the sensitivity of these channels to activating ligand could significantly alter the dynamics of phototransduction (for review, see Kramer and Molokanova, 2001), especially in cones (Rebrik et al., 2000). Modulation can occur by phosphorylation (Gordon et al., 1992; Molokanova et al., 1997, 1999) or by binding of ligands such as $\mathrm{Ca}^{2+} /$ calmodulin (Hsu and Molday, 1993; Bauer, 1996; Kosolapov and Bobkov, 1996) or by a related molecule (Hackos and Korenbrot, 1997; Rebrik and Korenbrot, 1998). We have shown that photoreceptor circadian 
oscillators cause cGMP-gated channels to have a higher affinity for cGMP during the subjective night (Ko et al., 2001). Given that DA is released in response to light and contributes to circadian control mechanisms in the intact retina, we have examined whether this neurohormone can also modulate cone cGMPgated channels.

\section{Materials and Methods}

Cell isolation and culture. Chick retinas were dissociated at embryonic day (E) 6 essentially as described by Adler and Hatlee (1989) and in an previous study from our laboratory (Ko et al., 2001). Briefly, E6 retinas were dissected and incubated in a solution consisting of (in mM): $123 \mathrm{NaCl}$, $5.36 \mathrm{KCl}, 9.51 \mathrm{Na}_{2} \mathrm{HPO}_{4}, 1.48 \mathrm{NaH}_{2} \mathrm{PO}_{4}, 0.1 \mathrm{gm} / \mathrm{ml}$ glucose, and 0.5 $\mathrm{mg} / \mathrm{ml}$ trypsin at $37^{\circ} \mathrm{C}$ for $25 \mathrm{~min}$ and then dissociated by trituration using a fire-polished Pasteur pipette. Retinal cells were grown for $5 \mathrm{~d}$ on poly-D-lysine-coated glass coverslips in a medium consisting of Eagle's minimal essential medium (Biowhittaker, Walkersville, MD) supplemented with $10 \%$ heat-inactivated horse serum (Biowhittaker), $2 \mathrm{~mm}$ glutamine, $50 \mathrm{U} / \mathrm{ml}$ penicillin, $50 \mu \mathrm{g} / \mathrm{ml}$ streptomycin, and $20 \mathrm{ng} / \mathrm{ml}$ recombinant rat ciliary neurotrophic factor (R\&D Systems, Minneapolis, $\mathrm{MN}$ ). Cultures prepared in this way yield a highly enriched population of cones (Adler et al., 1984; Belecky-Adams et al., 1996). Cell culture incubators $\left(39^{\circ} \mathrm{C}\right.$ and $\left.5 \% \mathrm{CO}_{2}\right)$ were equipped with lights and timers, which allowed for entrainment of retinal circadian oscillators to $12 \mathrm{hr}$ light/dark (LD) cycles in vitro as described previously (Ko et al., 2001). All experiments were performed on the second day of constant darkness (DD), after $4 \mathrm{~d}$ of entrainment to LD cycles. In DD, circadian time (CT) 0 is the time of expected lights on, and CT 12 is the time of expected lights off.

Electrophysiology. Recordings were made from cells with elongated cell bodies, an outer segment, and one or more prominent oil droplets on the distal side of the soma as described in detail previously (Dryer and Henderson, 1991, 1993; Ko et al., 2001). Briefly, inside-out patches were excised into a saline solution free of divalent cations consisting of (in mm): $145 \mathrm{NaCl}, 10 \mathrm{Na}$-HEPES, 10 glucose, 1 EGTA, pH 7.4, and held at $-65 \mathrm{mV}$. Pipette solution was the same as the bath saline. Recordings were performed in the light at room temperature $\left(22-23^{\circ} \mathrm{C}\right)$. Only one patch was excised from any given cell within $20-40$ min of removing cells from the incubator. Channels were activated by gravity-fed bath application of varying concentrations of cGMP dissolved in bath saline. Cultures were typically pretreated with drugs at CT 3 or CT 15 for $1-2 \mathrm{hr}$ or $15 \mathrm{~min}$ before recording. Drug treatment occurred in the dark. Data were stored on magnetic tape in FM mode before off-line digitization at 20 $\mathrm{kHz}$ (Axoscope, Axon Instruments, Foster City, CA) and analysis (Fetchan, Axon Instruments). Concentration-response curves were fitted with the Hill equation $I_{\mathrm{s}}=I_{\mathrm{Max}}\left[S^{n} /\left(K_{\mathrm{D}}{ }^{n}+S^{n}\right)\right]$, where $S$ is the concentration of cGMP, $K_{\mathrm{D}}$ is the dissociation constant, and $n$ is the Hill coefficient using Microcal Origin v6.0 software (Northhampton, MA). Each group contained 9-12 patches obtained from at least three different preparations of retinal cells. All statistical analyses were performed using Statistica sofware (Statsoft, Tulsa, OK) and consisted of Student's unpaired $t$ test or one-way ANOVA followed by Tukey's post hoc test for unbalanced $n$ (when comparisons were made between multiple independent groups). Throughout, $p<0.05$ was regarded as significant. Quinpirole was obtained from Tocris. All other DA receptor agonists and antagonists, as well as pertussis toxin (PTX), were obtained from Sigma (St. Louis, MO). This particular lot of PTX is biologically active, which we confirmed in other biological systems that are routinely studied in our laboratory.

Immunoblot analysis of protein kinase phosphorylation. These procedures have been described in detail previously (Ko et al., 2001). Briefly, chick retinal cells were entrained in vitro as described above. At various times on the second day of DD, dissociated retinal cells were washed in ice-cold PBS and lysed in $2 \times$ Laemmli sample buffer. Samples were boiled for $5 \mathrm{~min}$, separated by SDS-PAGE on $10 \%$ gels, transferred to nitrocellulose membranes, blocked overnight in PBS containing $0.3 \%$ Tween 20 and $6.5 \%$ nonfat dried milk, and then incubated with a monoclonal antibody specific for phosphorylated (Thr-286) $\mathrm{Ca}^{2+} /$ calmodulin-dependent protein kinase II (CaMKII) $\alpha$ subunit (RBI/Sig- ma), a monoclonal antibody specific for diphospho-extracellular signalrelated kinase (Erk) (Sigma), or a polyclonal antibody insensitive to the phosphorylation state of Erk (Santa Cruz Biochemicals, Santa Cruz, CA). Primary antibodies were used at a dilution of 1:1000. As noted previously (Ko et al., 2001), the CaMKII $\alpha$ subunit signal is composed of two bands because two splice variants of this enzyme are expressed in chick retina. Quantitation of CaMKII signal was based on the dominant smaller molecular weight form. Blots were analyzed using anti-mouse and antirabbit secondary antibodies conjugated to horseradish peroxidase and an ECL detection system (Amersham, Buckinghamshire, UK). The ratio of diphospho-Erk to total Erk, or phosphorylated CaMKII to total Erk, in each sample was determined by densitometry using Scion Image software (Scion Corp, Frederick, MD). All experiments were repeated three to six times. In most experiments, analyses of total Erk, diphospho-Erk, and/or phospho-CaMKII were performed on a single blot, which was stripped and reprobed with other primary antibodies.

Quantitative real-time reverse transcription-PCR analysis of $\mathrm{cPer} 2$ transcripts. Total RNA from cultured and intact chick retina was collected using a commercially available version of the guanadinium isothiocyanate method (Qiagen), and $500 \mathrm{ng}$ of total RNA from each sample was used to quantify expression of $c$ Per 2 and chick $\beta$-actin mRNA by quantitative real-time reverse transcription (RT)-PCR (Q-PCR) using the Taqman one-step RT-PCR kit and an ABI Prism 7000 Sequence Detection System (Applied Biosystems). An 89 bp fragment of $c$ Per 2 was obtained by standard RT-PCR using the following matched primers: 5'-CGG-GTC-CCT-TAA-ATG-AAG-ATG-TT-3' (forward) and 5' TTG-CTC-TGT-GAT-CTC-CTG-AAC-ACT-3' (reverse), which were designed on the basis of the sequence reported by Okano et al. (2001). The $c$ Per2 Q-PCR probe (5'-ATA-CGG-AGG-ACA-GAA-TC-3') recognized a $17 \mathrm{bp}$ region within the $89 \mathrm{bp}$ fragment between the primer binding sites. A $62 \mathrm{bp}$ fragment for $\beta$-actin was obtained by standard RT-PCR using the following matched primers: 5'-AAG-CCC-AGAGCA-AAA-GAG-GTA-TC-3' (forward) and 5'-GGT-GCA-AAT-ACCGTG-TTC-AAT-GG-3', which were designed on the basis of the sequence reported in GenBank (accession number L08165). The $\beta$-actin Q-PCR probe (5'-CTG-ACC-CTG-AAG-TAC-3') recognized a $15 \mathrm{bp}$ region between the primer binding sites. All primers and probes were made by Applied Biosystems. Each probe includes a $5^{\prime}$ reporter dye (FAM) and a $3^{\prime}$ quencher dye (TAMRA). During the PCR reactions, cleavage of the probe separates the reporter and quencher dyes, resulting in increased fluorescence of the reporter. Accumulation of PCR products is detected directly by monitoring the increase in fluorescence from the reporter dye. Data are expressed as the ratio of cPer 2 to $\beta$-actin, which serves as a loading control. All measurements were repeated three times.

\section{Results \\ Modulation of cone cGMP-gated channels by dopamine and D2 agonist}

Chick cones were entrained to $12 \mathrm{hr} L D$ cycles for $4-5 \mathrm{~d}$ in vitro and then switched to DD. On the second day of DD, inside-out patches were excised from cones during the subjective day (CT $4-7$ ) or the subjective night (CT 16-19), and cGMP concentration-response curves were generated immediately after patch excision and fitted with the Hill equation (Fig. $1 A$ ). As described previously (Ko et al., 2001), the mean $K_{\mathrm{D}}$ for cGMP was significantly $(p<0.001)$ greater in patches excised during the subjective day (CT 4-7) than during the subjective night (CT 16-19) (Fig. 1B), and the affinity of cGMP-gated channels for their normal activating ligand was under circadian control.

The synthesis and secretion of DA is also under circadian control in the avian retina and is higher during the subjective day or after acute light exposure during the subjective night (Adachi et al., 1998). We have observed that DA evokes a phasedependent modulation of cGMP-gated channels in chick cone photoreceptors. In these experiments, drugs were applied 1.5-2 $\mathrm{hr}$ before inside-out patch recordings were made from cultured cones on the second day of DD after 4-5 d of LD entrainment. 
A.

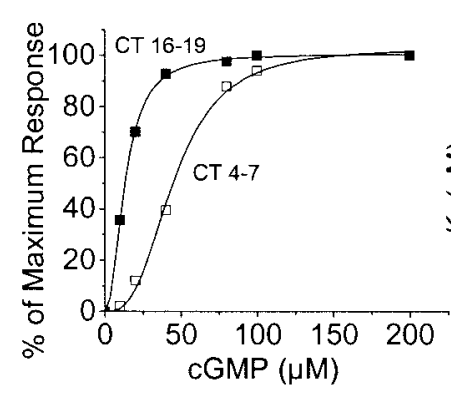

B.

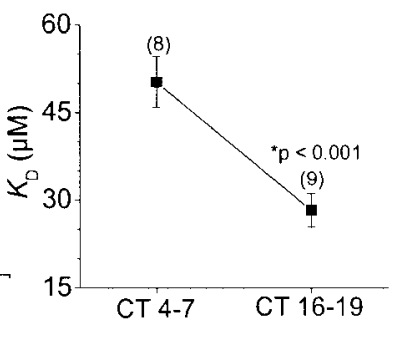

Figure 1. Circadian rhythm in the apparent affinity of cGMP-gated channels for activating ligand in chick retinal cone photoreceptors. Cultured chick cones were entrained to $12 \mathrm{hr}$ LD cycles for $4-5 \mathrm{~d}$ in vitro and then switched to $\mathrm{DD}$. 0 n the second day of $\mathrm{DD}$, inside-out patches were excised from cones during the subjective day (CT 4 -7) or the subjective night (CT 16-19). cGMP concentration-response curves were generated immediately after patch excision. $A$, Typical cGMP concentration-response curves obtained from patches excised during the subjective day $(\square)$ and subjective night $(\square)$. Curves are shown with superimposed least-squares fits to the Hill equation. $B$, Mean $K_{D}$ values from patches excised at CT $4-7$ ( $n=8$ patches) and CT $16-19(n=9$ patches $)$ in cells free-running on the second day of DD. In this and all subsequent figures, error bars represent SEM, numbers in parentheses are the number of patches tested, and asterisks indicate $p<0.05$.

Application of $500 \mathrm{~nm}$ DA for $2 \mathrm{hr}$ before patch excision had no effect on cGMP-gated channels in patches excised during the subjective day (CT 4-7). However, $2 \mathrm{hr}$ exposure to DA caused a significant $(p<0.05)$ increase in the $K_{\mathrm{D}}$ of cGMP-gated channels in patches excised during the subjective night (CT 16-19) (Fig. $2 A$ ). This effect is mediated by D2 receptors. Thus, a $2 \mathrm{hr}$ treatment with the $\mathrm{D} 2$ receptor agonist quinpirole $(500 \mathrm{~nm})$ also evoked phase-dependent modulation of cGMP-gated channels (Fig. $2 \mathrm{~B}$ ). Moreover, pretreatment with the $\mathrm{D} 2$ antagonist eticlopride $(50 \mu \mathrm{M}$ ) blocked the effect of DA (Fig. 2C), but application of eticlopride by itself had no effect on channel affinity at either time of day (Fig. 2D). Finally, treatment with the D1 antagonist SCH $23390(50 \mu \mathrm{M})$ did not alter the effect of DA (Fig. 2E), and the D1 agonist SKF $38393(1 \mu \mathrm{M})$ had no effect on channel affinity at any time of day (Fig. 2F). None of these perturbations altered the Hill slope for channel activation or the average number of channels detected per patch (data not shown). In summary, $2 \mathrm{hr}$ of continuous activation of D2 receptors, but not D1 receptors, can modulate cone photoreceptor cGMP-gated channels by lowering the affinity for activating ligand during the subjective night (CT 16-19). Sustained D2 stimulation has no effect during the subjective day (CT 4-7), when the channels are already in a lowaffinity state.

Previously we have shown that photoreceptors that have never been entrained to LD cycles do not display daily rhythms in the affinity of cGMP-gated channels (Ko et al., 2001). We investigated whether DA can modulate cGMP-gated channels in nonentrained photoreceptors that have been cultured under continuous light for $5 \mathrm{~d}$ after dissociation. On the fifth day in vitro, DA (500 nM) or vehicle was applied for $2 \mathrm{hr}$ before patch excision at various times of day. Note that the mean $K_{\mathrm{D}}$ for channel activation in nonentrained cells normally lies at an intermediate level just below that observed during the subjective day in entrained cells [see also Ko et al. (2001)]. We were surprised to find that $2 \mathrm{hr}$ exposure to DA evoked a significant decrease in the mean $K_{\mathrm{D}}$ of the cGMP-gated channels from nonentrained cells cultured in continuous light (control, $K_{\mathrm{D}}=37.3 \pm 4.2 \mu \mathrm{M}, n=15$; DAtreated cells, $K_{\mathrm{D}}=25.3 \pm 1.9 \mu \mathrm{M}, n=16 ; p<0.05$ ). These data reveal unexpected complexity in the actions of DA on cGMP-


Figure 2. Modulation of CGMP-gated channels by DA is mediated by D2 receptors. Experiments were performed on $L D$ entrained cones free-running on the second day of $D D$. All drugs were applied starting $1.5-2 \mathrm{hr}$ before inside-out patch recordings were made at CT $4-7$ and CT $16-19$. Agonists and antagonists were dissolved in a vehicle containing $0.4 \%$ ascorbic acid. $A$, Dopamine significantly increased the $K_{D}$ of $C G M P$-gated channels during the subjective night (CT 16-19) but not the subjective day (CT 4-7) compared with the controls. A similar phasedependent effect was produced by the selective $\mathrm{D} 2$ agonist quinpirole $(B)$. The $\mathrm{D} 2$ antagonist eticlopride $(50 \mu \mathrm{m})$ blocked the effect of dopamine ( $(C$, but treatment with eticlopride by itself had no effect on cGMP-gated channels (D). The selective D1 antagonist SCH $23390(50 \mu \mathrm{M})$ did not reverse the effect of dopamine $(E)$, and the selective D1 agonist SKF $38393(1 \mu \mathrm{M})$ had no effect on cGMP-gated channels ( $F$ ). In this and subsequent figures, all data points are means of $8-10$ patches and derived from at least three different cell preparations.

gated channels, because $2 \mathrm{hr}$ of DA exposure does not decrease mean $K_{\mathrm{D}}$ at any time of day in cells previously exposed to entraining $\mathrm{LD}$ cycles. One possible explanation for this result is that the circadian oscillator in some way controls the transduction cascade used by D2 receptors. Additional evidence for this will be presented below.

\section{Dopamine and D2 agonist effects on Erk and CaMKII phosphorylation in cones photoreceptors}

We have shown previously that circadian control of cone cGMPgated channels is mediated through the MAP kinase Erk, which is more active during the subjective night, and CaMKII, which is more active during the subjective day (Ko et al., 2001). In the present experiments, chick embryos were entrained in ovo to LD for $4-5 \mathrm{~d}$ as described previously (Ko et al., 2001), and retinal cells were then dissociated and allowed to free-run in DD. On the second day of DD, cells were treated with DA (500 nM) or quin- 
A.

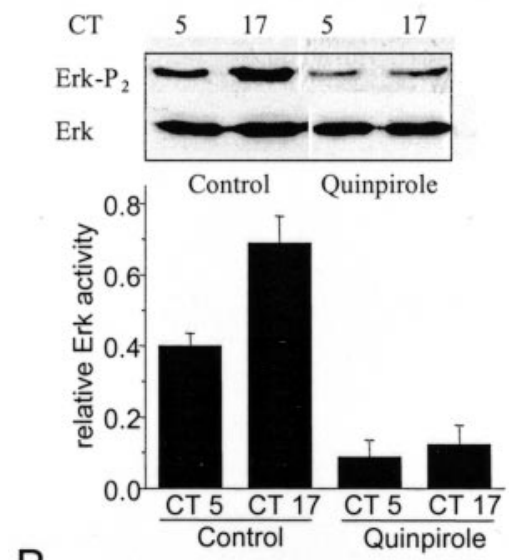

B.
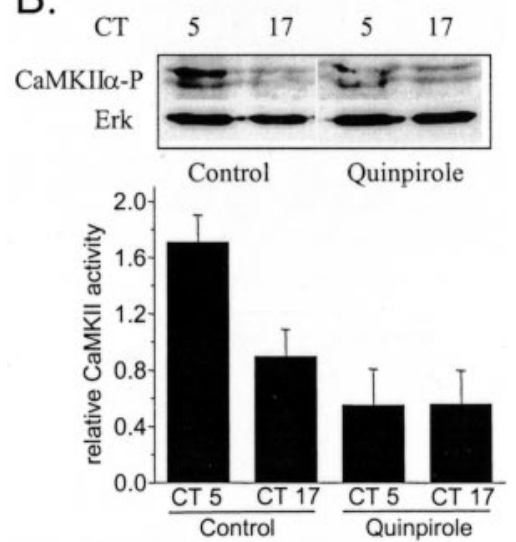

Figure 3. A selective D2 agonist modulates Erk and CaMKII activation in chick cones. Chick retinal cells free-running on the second day of $D D$ were treated with the $D 2$ agonist quinpirole (500 nM) or vehicle for $2 \mathrm{hr}$ starting at CT 3 or CT 15. At CT 5 or CT 17, cells were lysed and harvested for immunoblot analysis of Erk and CaMKII phosphorylation using antibodies selective for the phosphorylated forms of these proteins, as well as with antibodies that recognize total Erk regardless of its phosphorylation state. $A$, Erk diphosphorylation is substantially greater during the subjective night (CT 17) than during the subjective day (CT 5) in control cells. Cells treated for $2 \mathrm{hr}$ with the $\mathrm{D} 2$ agonist quinpirole exhibit diminished Erk diphosphorylation during both the subjective night (CT 17) and the subjective day (CT 5). B, CaMKII phosphorylation is greater during the subjective day (CT 5) than during the subjective night (CT 17) in control cells. Treatment with $500 \mathrm{~nm}$ quinpirole for $2 \mathrm{hr}$ dampened the rhythm in CaMKII phosphorylation, which was decreased during both the subjective day (CT 5) and the subjective night (CT 17). In this figure, representative blots are shown above results of densitometric analysis of five repetitions of each experiment. Ordinates of the graphs represent signal for phosphorylated enzyme divided by total Erk.

pirole (500 nM) for $2 \mathrm{hr}$ starting at CT 3 or CT 15 . At CT 5 or CT 17, cells were lysed, and Erk and CaMKII phosphorylation were determined by immunoblot analysis. As described previously (Ko et al., 2001), Erk diphosphorylation was substantially greater during the subjective night (CT 17) than during the subjective day (CT 5) in control cells (Fig. 3A). A 2 hr exposure to the D2 agonist quinpirole diminished Erk diphosphorylation during both the subjective night (CT 17) and the subjective day (CT 5) (Fig. 3A), although the effect was greater during the night. DA produced identical effects (Fig. 4A). Because it is the diphosphorylated form of Erk that is active, these data indicate that continuous activation of D2 receptors can inhibit Erk activity. D2 agonists also affected the phosphorylation of CaMKII. Note that CaMKII phosphorylation is normally greater during the subjective day (CT 5) than during the subjective night (CT 17) (Fig. 3B), but this rhythm was markedly dampened in quinpirole-treated
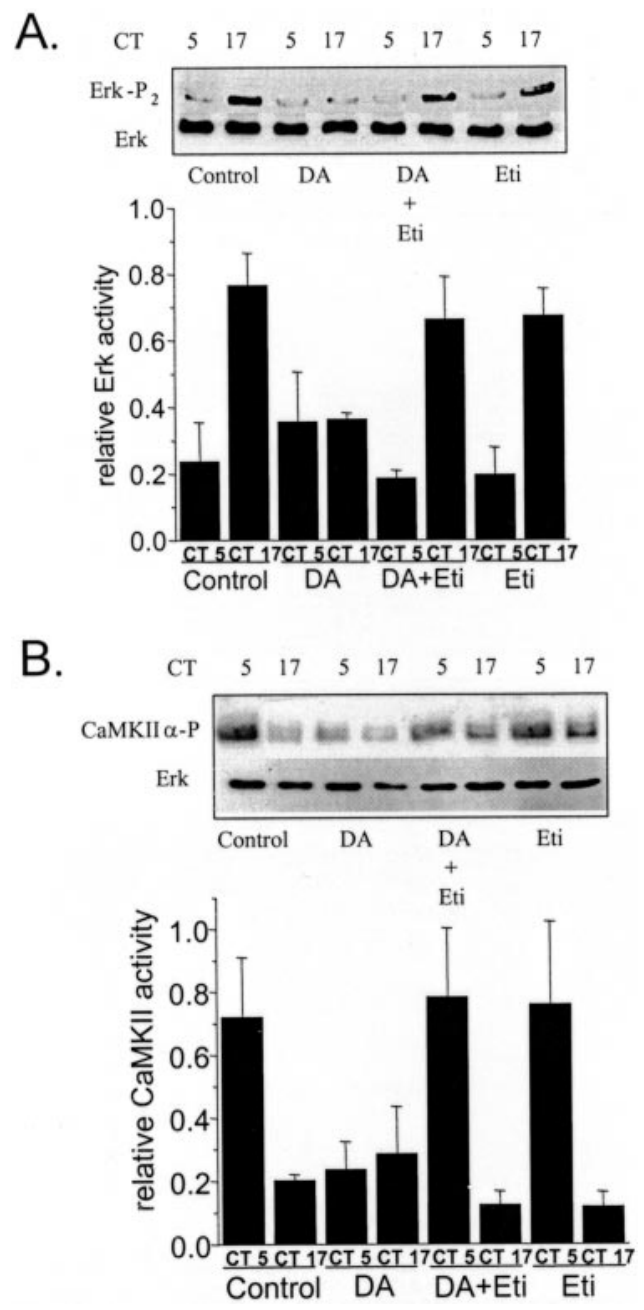

Figure 4. The effects of DA on Erk and CaMKII phosphorylation are blocked by the D2 antagonist eticlopride. Vehicle, DA (500 $\mu \mathrm{m}$ ), eticlopride (50 $\mu \mathrm{m})$, or a combination of the two drugs was applied at CT 3 and CT 15, and cells were lysed and harvested at CT 5 and CT 17. Analyses of protein phosphorylation were performed by immunoblot analysis as described for Figure 3. Bar graphs represent results of five repetitions of each experiment, showing the ratio of phosphorylated enzyme divided by total Erk as determined by densitometry.

cells (Fig. 3B) and in DA-treated cells (Fig. 4B). Thus, sustained activation of D2 receptors dampens the circadian rhythms of both Erk and CaMKII phosphorylation. It also bears noting that the effects of DA on Erk and CaMKII are blocked by the D2 antagonist eticlopride (Fig. 4).

The cellular effects of $\mathrm{D} 2$ receptor activation are gated by the circadian oscillator

The inhibitory effect of D2 agonists on Erk activation in photoreceptors is consistent with the electrophysiological data in Figure 2, along with our previous observation that high Erk activity is temporally correlated with high channel affinity (Ko et al., 2001). On the other hand, D2 agonists evoke a transient activation of Erk in almost every other system tested, including several neural and glial cell populations (Luo et al., 1998; Yan et al., 1999; Cai et al., 2000). These earlier studies used DA treatments that are considerably shorter than those used in the experiments described above. Therefore, we examined whether the effects of DA on entrained chick cone photoreceptors depend on the duration of agonist treatment as well as the time of day. We observed that a 15 min exposure to $500 \mathrm{~nm}$ DA on the second day of DD caused 


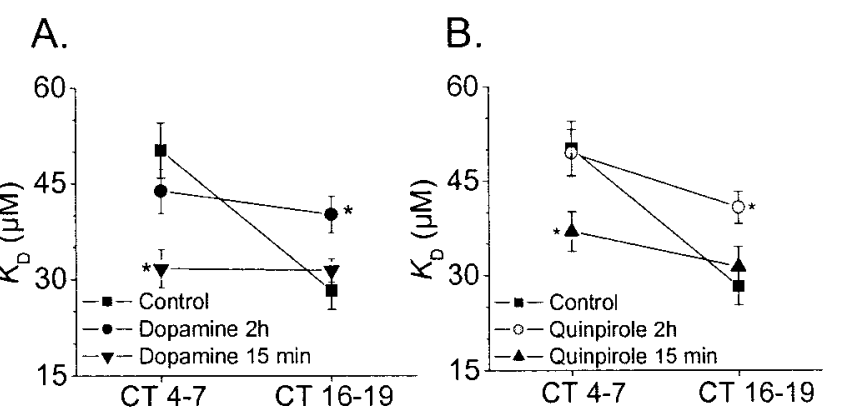

Figure 5. The effects of dopamine agonists depend on the duration of receptor activation. Cultured chick cones free-running on the second day of DD were treated with dopamine (500 $\mathrm{nm}$ ), quinpirole ( $500 \mathrm{~nm}$ ), or vehicle for $15 \mathrm{~min}$ or $2 \mathrm{hr}$ before excision of inside-out patches and determination of channel $K_{D}$. A, Treatment with DA for 15 min caused a significant decrease in CGMP-gated channel $K_{D}$ during the subjective day (CT 4-7) but had no effect during the subjective night (CT 16-19) compared with controls. In contrast, treatment with dopamine for $2 \mathrm{hr}$ significantly increased the $K_{\mathrm{D}}$ of cGMP-gated channels during the subjective night (CT 16-19) but had no effect during the subjective day (CT 4-7) compared with the controls. B, A similar pattern is observed in cells treated with the $D 2$ agonist quinpirole. All data points are means of 8-10 patches and are derived from at least three different cell preparations.

a decrease in channel $K_{\mathrm{D}}$ during the subjective day (CT 4-7) but had virtually no effect during the subjective night (CT 16-19). In contrast, a $2 \mathrm{hr}$ exposure to DA caused an increase in channel $K_{\mathrm{D}}$ during the subjective night (CT 16-19) but had no effect during the subjective day (CT 4-7) (Fig. 5A). An identical pattern was observed with the D2 agonist quinpirole (500 nM) (Fig. 5B). In other words, the acute $(15 \mathrm{~min})$ effects of D2 receptor activation are the opposite of those observed with a more sustained $(2 \mathrm{hr}$ ) activation of these receptors in entrained cells. Moreover, the results with acute DA treatments in entrained cells are similar to those evoked by more sustained D2 receptor activation in nonentrained cells. This pattern, although somewhat complex, provides additional evidence that the transduction cascade used by D2 receptor activation is in some way gated by the circadian oscillator.

To test this theory more directly, we examined the time course of D2 receptor effects on Erk and CaMKII phosphorylation during the subjective day (CT 5) and the subjective night (CT 17). During the subjective day, quinpirole treatment evoked a robust but transient increase in Erk phosphorylation that fell to slightly below the baseline after $2 \mathrm{hr}$, even in the continued presence of agonist (Fig. 6A). By contrast, during the subjective night, quinpirole treatment caused a more slowly developing but sustained decrease in Erk phosphorylation (Fig. 6A). We have observed that other pharmacological treatments (e.g., forskolin) can increase Erk phosphorylation even during the subjective night (our unpublished observations). This is significant because it indicates that the failure of DA to cause a transient stimulation of Erk during the nighttime is not because the system is already maximally activated. In other experiments, we observed that treatment with quinpirole evoked a transient increase of CaMKII phosphorylation during the subjective night but evoked a modest and slowly developing inhibition during the subjective day (Fig. $6 B$ ), i.e., the effects of quinpirole on Erk phosphorylation are antiphase to its effects on CaMKII. These experiments provide a second line of evidence that circadian phase regulates the nature of the transduction cascade responses to D2 receptor activation in cone photoreceptors.

On the other hand, the effects of $2 \mathrm{hr}$ exposure to DA are not associated with changes in the dynamic state of the circadian oscillator. We examined this specifically by measuring cPer2
A.


B.
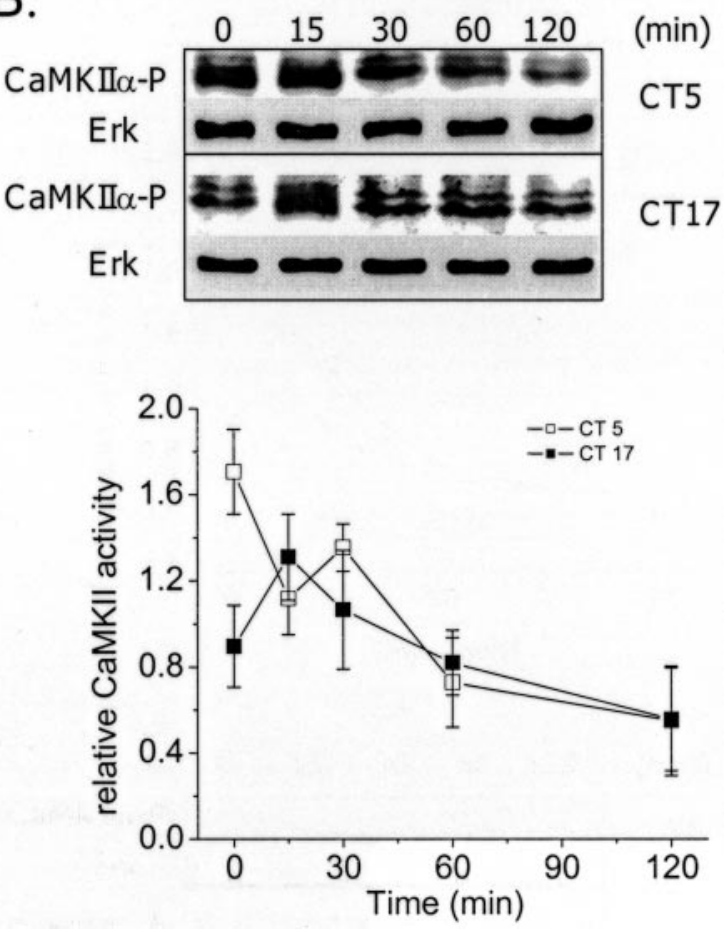

Figure 6. The time course of D2 receptor effects on Erk and CaMKII phosphorylation in chick photoreceptors. Cultured cone photoreceptors cells were treated with quinpirole ( $500 \mathrm{~nm}$ ) for 0 , $15,30,60$, or 120 min starting at CT 5 or CT 17. Cells were then lysed and harvested immediately for immunoblot analysis of Erk and CaMKII phosphorylation. A, During the subjective day (CT 5), quinpirole treatment evoked a robust but transient increase in Erk phosphorylation, which peaked at $15 \mathrm{~min}$ and fell to slightly below the baseline after $2 \mathrm{hr}$ of continuous treatment. In contrast, during the subjective night (CT 17), quinpirole treatment caused only the slowly developing but sustained decrease in Erk phosphorylation. Top panels show a typical immunoblot, and bottom panels are densitometric analyses of several repetitions of these experiments. $B$, Treatment with quinpirole evoked a transient increase of CaMKII phosphorylation during the subjective night (CT 17), which peaked at 15 min and gradually fell to baseline after $2 \mathrm{hr}$. In contrast, during the subjective day (CT 5), quinpirole treatment evoked only the slowly developing inhibition of CaMKII phosphorylation. 
A.

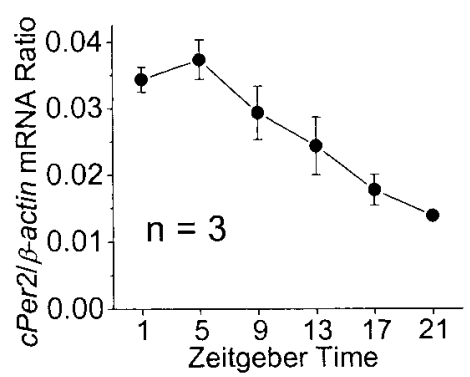

B.

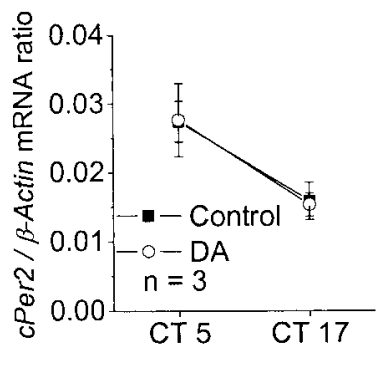

Figure 7. Exposure to DA for $2 \mathrm{hr}$ does not affect $C_{\text {Per2 }} \mathrm{mRNA}$ levels in embryonic chick retina. $A$, Expression of $C P$ er2 $\mathrm{mRNA}$ is rhythmic in chick retina. Whole retinas from entrained chick embryos were homogenized, and CPer2 transcript levels were quantified by Q-PCR. CPer2 is high during the subjective day and low during the subjective night. $B$, Cultured cone photoreceptors were treated with $500 \mathrm{~nm}$ dopamine or vehicle for $2 \mathrm{hr}$ starting at CT 3 or CT 15 on the second day of DD after $5 \mathrm{~d}$ of LD, and CPer2 mRNA was measured by Q-PCR at CT 5 and CT 17. Dopamine does not affect the circadian oscillation of $\mathrm{CPer} 2$ in cultured chick photoreceptors.

mRNA levels in cultured photoreceptors by means of real-time quantitative RT-PCR procedures. This transcript is rhythmically expressed in avian circadian oscillators systems, including those of birds (Doi et al., 2001), and can therefore serve as a readout of the dynamic state of the clock. As with avian pineal cells, cPer2 mRNA levels in retina on the second day of DD are highest during the subjective day (Fig. 7A). Exposure to DA for $2 \mathrm{hr}$ starting at CT 3 or CT 15 had no effect on $c$ Per2 transcript levels at either circadian phase (Fig. $7 B$ ). This is similar to results obtained previously in Xenopus retina, in which exposure to light or DA for at least $3 \mathrm{hr}$ is required to produce any detectable effect on circadian oscillator dynamics (Steenhard and Besharse, 2000).

\section{The effects of dopamine on cGMP-gated channels are not mediated by inhibition of cAMP production}

In retinal photoreceptors of chick, some of the effects of D2 receptor activation, e.g., inhibition of melatonin secretion and photomechanical movements, are mediated by inhibition of adenylate cyclase (Iuvone et al., 1990; Stenkamp et al., 1994). This raises the possibility that modulation of CGMP-gated channels occurs by a similar mechanism. This hypothesis predicts that agents that prevent or bypass the inhibition of cAMP production should reduce or eliminate the effects of DA on cGMP-gated channels. A similar strategy was used by Hasegawa and Cahill (1999) to show that cAMP is a component of the transduction pathway used by DA to shift the phase of the melatonin rhythm in Xenopus photoreceptors. To test this hypothesis, we applied DA in the presence and absence of $500 \mu \mathrm{M}$ 8(4-chlorophenylthio)cAMP (CPT-cAMP), a membrane-permeable analog of cAMP. Control cells were treated with CPT-CAMP alone or with vehicle alone (Fig. $8 \mathrm{~A}$ ). Treatments were started $2 \mathrm{hr}$ before patch excision at CT 4-7 or CT 16-19 in cells free-running on the second day of DD. Vehicle-treated cells exhibited a robust circadian modulation of channel $K_{\mathrm{D}}$. Importantly, treatment with CPTcAMP eliminated this rhythm by causing a marked and significant $(p<0.05)$ increase in channel affinity during the subjective day but not during the subjective night (Fig. $8 \mathrm{~A}$, compare open and filled circles). In other words, the channel locks into a highaffinity state. It bears noting that a similar effect is produced by 20 $\mu \mathrm{M}$ forskolin, an activator of adenylate cyclase (data not shown), and a detailed analysis of these observations will be the subject of a subsequent report. As noted earlier, DA evokes the opposite effect, i.e., there is a significant decrease in channel affinity during

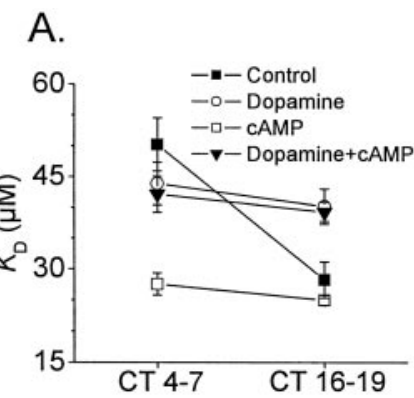

B.

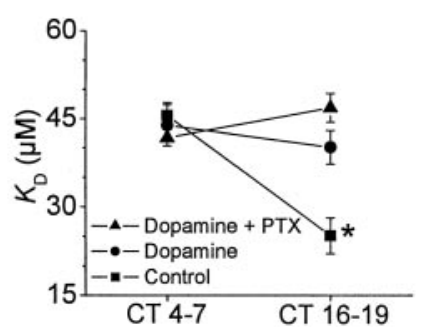

Figure 8. The effects of dopamine on cGMP-gated channels are not mediated by inhibition of cAMP production and are not sensitive to pertussis toxin. $A$, Control cells exhibit a robust circadian modulation of channel $K_{\mathrm{D}}$. Treatment with $500 \mu \mathrm{m}$ 8-CPT-CAMP (cAMP), a membrane-permeable analog of cAMP, caused a significant decrease in $K_{D}$ during the subjective day (CT 4-7) but not during the subjective night (CT 16-19) compared with controls. DA $(500 \mathrm{~nm})$ treatment evoked the opposite effect; i.e., there was a significant increase in $K_{D}$ during the subjective night but no effect during the subjective day. Treatment with DA ( $500 \mathrm{~nm})$ in the presence of $500 \mu \mathrm{m} 8$ 8-CPT-CAMP (Dopamine + CAMP) resulted in a significant increase in $K_{D}$ during the subjective night but no apparent effect during the subjective day; i.e., the effects were indistinguishable from those of DA alone. In this experiment, drugs were applied $1.5-2 \mathrm{hr}$ before inside-out patch recordings from cultured cones on the second day of DD. $B$, After pretreatment with $200 \mathrm{ng} / \mathrm{ml}$ pertussis toxin (PTX) for $18-24 \mathrm{hr}$, a subsequent $2 \mathrm{hr}$ exposure to DA evoked a modulation of cGMP-gated channels comparable with that observed in control cells. Pertussis toxin by itself had no effect on the affinity of cGMP channels. All data points are means of 8-10 patches and are derived from at least three different cell preparations.

the subjective night and no effect during the subjective day, and the channel locks into a low-affinity state. Most significantly, the same behavior is observed in cells exposed simultaneously to both DA and CPT-cAMP. In other words, continuous $2 \mathrm{hr}$ activation of $\mathrm{D} 2$ receptors evokes a decrease in channel affinity even when cAMP-responsive intracellular cascades are tonically activated by an efficacious and membrane-permeable cAMP agonist. Finally, it bears noting that the effects of DA are readily observed in photoreceptors cells pretreated overnight with $200 \mathrm{ng}$ of PTX (Fig. $8 B$ ). Previous studies have shown that PTX can block D2 receptor-mediated suppression of cAMP formation in this same preparation of chick photoreceptors (Iuvone et al., 1990). These data therefore provide direct evidence for multiple pathways leading out of D2 dopamine receptors in cone photoreceptors.

\section{Discussion}

In the vertebrate retina, a substantial body of evidence indicates that DA facilitates the transitions between the rod-dominated signaling pathways characteristic of scotopic conditions and the cone-dominated pathways that operate under photopic conditions (for review, see Djamgoz and Wagner, 1992; Krizaj, 2000). DA interacts with photoreceptor circadian control mechanisms, and its secretion and actions vary with the time of day. In birds and other vertebrates, retinal DA secretion is increased during the subjective day, even in constant darkness (Adachi et al., 1998), and is therefore a secondary output of the photoreceptor clock. DA can also entrain photoreceptor circadian oscillators, with phase-dependent effects that are similar but not identical to those of light itself (Cahill and Besharse, 1995; Hasegawa and Cahill, 1999; Steenhard and Besharse, 2000). Thus, DA can also be regarded as an input to the retinal circadian clock. On theoretical grounds, the existence of a single variable that is both an input and an output of a circadian clock has been proposed to contribute to the stability and robustness of circadian oscillator systems (Roenneberg and Merrow, 1999). In addition, retinal DA secretion is increased by brief light pulses or flickering light stimuli (Djamgoz and Wagner, 1992; Adachi et al., 1998), and DA pro- 
duces a number of acute effects in the inner and outer retina that are unrelated to entrainment of circadian oscillators but contribute to the overall light-adaptive state of the retina (for review, see Besharse and Iuvone, 1992; Cahill and Besharse, 1995).

In the present study we have examined modulation by DA of cGMP-gated channels in cone photoreceptors, which are under the control of circadian oscillators intrinsic to these cells (Ko et al., 2001). These channels are of special interest because they carry the dark current and have a substantial permeability to $\mathrm{Ca}^{2+}$ ions (Picones and Korenbrot, 1992; Frings et al., 1995). In addition to mediation of phototransduction, activation of cGMP-gated channels can also stimulate exocytosis of transmitter from cone synaptic terminals (Rieke and Schwartz, 1994; Savchenko et al., 1997). We have previously presented theoretical calculations suggesting that that modulation of chick cone cGMP-gated channels should have significant effects on the amplitude of the cone dark current at physiological levels of intracellular cGMP, and thereby on the dynamics of phototransduction (Ko et al., 2001; Kramer and Molokanova, 2001).

The biochemical and physiological observations in this study reduce to two main conclusions: (1) DA can modulate the photoreceptor ionic channels that carry the dark current, possibly by direct phosphorylation of the channels, and (2) the nature of the response to DA is regulated by the circadian oscillator and can itself be considered as an output of the clock. More specifically, the state of the circadian oscillator appears to determine whether D2 receptor activation causes activation or inhibition of the Erk form of MAP kinase. Other biochemical and physiological effects, including modulation of cGMP-gated channels, are probably consequences of those processes (Ko et al., 2001).

Consistent with this last conclusion, we observed that a $2 \mathrm{hr}$ exposure to D2 agonists has no effect during the subjective day, when cGMP-gated channels are already in a low-affinity state because of the action of endogenous circadian oscillators (Ko et al., 2001). We also observed that a $15 \mathrm{~min}$ exposure to DA evokes an increase in channel affinity during the subjective day but not during the subjective night. Thus, D2 receptor responses and circadian output mechanisms effectively occlude, suggesting that these processes may share common mechanisms. Moreover, DA modulation evoked by either brief or sustained activation of D2 receptors resembles circadian control mechanisms in affecting only the $K_{\mathrm{D}}$ for channel activation, and not the Hill slope or the average number of channels detected per patch (data not shown). The molecular modifications that result in modulation of the channels are unknown but could include direct phosphorylation of the channels (Gordon et al., 1992; Molokanova et al., 1997, 1999) or binding of modulatory ligands such as $\mathrm{Ca}^{2+}$-binding proteins (Hsu and Molday, 1993; Bauer, 1996; Kosolapov and Bobkov, 1996). In this regard, direct modulation of Kv4 family channels by Erk has been described in other cell types (Adams et al., 2000), and it is possible that cGMP-gated channel complexes are direct substrates for Erk or CaMKII or both.

The electrophysiological recordings in these experiments were performed immediately after the termination of DA or quinpirole treatment and not on subsequent circadian days when the consequences of clock phase-shifting are usually observed (Shearman et al., 2000). This experimental design was chosen specifically because it does not allow time for DA to produce significant changes in the overall configuration of circadian oscillator transcription-translation feedback loops. In confirmation of this, we observed that $2 \mathrm{hr}$ of DA treatment had no effect on expression of a rhythmic clock gene transcript (cPer2) in cultured chick photoreceptors. Therefore the results described here cannot be attributed to clock phase-shifting (which in any case would not normally be observed until subsequent cycles). Instead, these results are consistent with the existence of multiple D2 receptor signaling cascades that are regulated independently as an output of the circadian oscillator.

It is well established that D2 receptors mediate inhibition of cAMP formation in retinal photoreceptors (Iuvone, 1986; Iuvone et al., 1990; Stenkamp et al., 1994). However, we observed that DA could still evoke a "light-like" modulation of cGMP-gated channels in the presence of a membrane-permeable cAMP analog that by itself is able to modulate the channels in the opposite direction. This result indicates that dopaminergic modulation of the channels occurs by a different mechanism, i.e., one that does not entail inhibition of adenylate cyclase. Moreover, the DA effects observed here are resistant to pertussis toxin, which blocks D2 receptor-mediated inhibition of adenylate cyclase in most systems (Huff, 1996), including cultured chick photoreceptors (Iuvone et al., 1990). We are unaware of previous reports of D2 receptor family-mediated inhibition of Erk signaling in any system such as we observe with $2 \mathrm{hr}$ of agonist treatment during the subjective night. However, there are several reports of D2 agonists evoking transient increases in Erk phosphorylation in neuronal and non-neuronal cells (Luo et al., 1998; Yan et al., 1999; Cai et al., 2000; Oak et al., 2001). We also observed that shortduration exposures (e.g., $15 \mathrm{~min}$ ) to DA or quinpirole evoked transient increases in Erk phosphorylation during the subjective day but not during the subjective night.

To our knowledge, studies on Erk responses to a more sustained stimulation of D2 receptors have not appeared. There is evidence that regulation of Erk MAP kinase by D2-like DA receptors and other G-protein-coupled receptors requires receptor sequestration (Della Rocca et al., 1999; Ignatova et al., 1999; Maudsley et al., 2000), in some cases mediated by trans-regulation of tyrosine kinase receptors (Pierce et al., 2000; Oak et al., 2001). These observations suggest a broad class of models that could explain the results obtained here, i.e., that the inhibition of Erk seen after $2 \mathrm{hr}$ DA treatment is mediated by receptors that have been sequestered for a considerable period of time. It is also possible that chick photoreceptors express multiple types of D2 family receptors that are coupled to different transduction cascades that converge onto Erk with a different time course and produce qualitatively different effects on this pathway.

Previous studies of retinal circadian control mechanisms have shown that photoreceptor oscillators can drive rhythmic outputs in the absence of other cell types (Cahill and Besharse, 1993; Pierce et al., 1993; Ko et al., 2001). These observations are consistent with the present observation that circadian rhythms in channel gating persist in the presence of the D2 antagonist eticlopride. This result is not surprising because the culture conditions used here yield a highly enriched population of cones, and DAcontaining cells are not present in any significant number (Adler et al., 1984; Adler and Hatlee, 1989). However, in the intact retina it is clear that DA acting through D2 family receptors plays an important role in overall circadian control mechanisms, especially in the circadian regulation of rod-cone dominance as accessed by recordings of electroretinogram b-waves in birds (Manglapus et al., 1998, 1999), and direct recordings of horizontal cells in teleosts (Ribelayga et al., 2002).

As described previously (Ko et al., 2001), modulation of cGMP-gated channels should produce significant effects on the photoreceptor dark current and thereby on the dynamics of phototransduction. It is possible that modulation of cone cGMPgated channels by circadian clocks and by DA causes an indirect 
effect on rod-cone coupling, possibly as a consequence of altered $\mathrm{Ca}^{2+}$ homeostasis and changes in transmitter secretion from the synaptic region (Miller and Korenbrot, 1993; Rieke and Schwartz, 1994; Savchenko et al., 1997), and in this way contributes to the daily changes in cone function that contribute to circadian control of the avian retina.

In summary, we have shown that DA acting through D2 receptors can modulate cone cGMP-gated channels. The nature of the response depends on the time of day and the duration of agonist treatment, and it appears that the qualitative nature of the transduction pathway used by $\mathrm{D} 2$ dopamine receptors is under circadian control.

\section{References}

Adachi A, Nogi T, Ebihara S (1998) Phase-relationship and mutual effects between circadian rhythms of ocular melatonin and dopamine in the pigeon. Brain Res 792:361-369.

Adams JP, Anderson AE, Varga AW, Dineley KT, Cook RG, Pfaffinger PJ, Sweatt JD (2000) The A-type potassium channel Kv4.2 is a substrate for the mitogen-activated protein kinase ERK. J Neurochem 75:2277-2287.

Adler R, Hatlee M (1989) Plasticity and differentiation of embryonic retinal cells after terminal mitosis. Science 243:391-393.

Adler R, Lindsey JD, Elsner CL (1984) Expression of cone-like properties by chick embryo neural retina cells in glial-free monolayer cultures. J Cell Biol 99:1173-1178.

Bauer PJ (1996) Cyclic GMP-gated channels of bovine rod photoreceptors: affinity, density and stoichiometry of $\mathrm{Ca}^{2+}$-calmodulin binding sites. J Physiol (Lond) 494:675-685.

Belecky-Adams T, Cook B, Adler R (1996) Correlations between terminal mitosis and differentiated fate of retinal precursor cells in vivo and in vitro: analysis with the "window-labeling" technique. Dev Biol 178:304-315.

Besharse JC, Iuvone PM (1992) Is dopamine a light-adaptive or darkadaptive modulator in retina? Neurochem Int 20:193-199.

Burns ME, Baylor DA (2001) Activation, deactivation, and adaptation in vertebrate photoreceptor cells. Annu Rev Neurosci 24:779-805.

Burnside B, Wang E, Pagh-Roehl K, Rey H (1993) Retinomotor movements in isolated teleost retinal cone inner-outer segment preparations (CISCOS); effects of light, dark, and dopamine. Exp Eye Res 57:709-722.

Cahill GM, Besharse JC (1991) Resetting the circadian clock in cultured Xenopus eyecups: regulation of retinal melatonin rhythms by light and D2 dopamine receptors. J Neurosci 11:2959-2971.

Cahill GM, Besharse JC (1993) Circadian clock functions localized in Xenopus retinal photoreceptors. Neuron 10:573-577.

Cahill GM, Besharse JC (1995) Circadian rhythmicity in vertebrate retinas: regulation by a photoreceptor oscillator. Prog Retin Eye Res 14:267-291.

Cai G, Zhen X, Uryu K, Friedman E (2000) Activation of extracellular signalregulated protein kinases is associated with a sensitized locomotor response to D2 dopamine receptor stimulation in unilateral 6-hydroxydopaminelesioned rats. J Neurosci 20:1849-1857.

Della Rocca GJ, Mukhin YV, Garnovskaya MN, Daaka Y, Clark GJ, Luttrell LM, Lefkowitz RJ, Raymond JR (1999) Serotonin 5-HT1A receptormediated Erk activation requires calcium/calmodulin-dependent receptor endocytosis. J Biol Chem 274:4749-4753.

Djamgoz MB, Wagner HJ (1992) Localization and function of dopamine in the adult vertebrate retina. Neurochem Int 20:139-191.

Doi M, Nakajima Y, Okano T, Fukada Y (2001) Light-induced phase-delay of the chicken pineal circadian clock is associated with the induction of cE4bp4, a potential transcriptional repressor of $c P e r 2$ gene. Proc Natl Acad Sci USA 98:8089-8094.

Dryer SE, Henderson D (1991) A cyclic GMP-activated channel in dissociated cells of the chick pineal gland. Nature 353:756-758.

Dryer SE, Henderson D (1993) Cyclic GMP-activated channels of the chick pineal gland: effects of divalent cations, $\mathrm{pH}$, and cyclic AMP. J Comp Physiol [A] 172:271-279.

Fain GL, Matthews HR, Cornwall MC, Koutalos Y (2001) Adaptation in vertebrate photoreceptors. Physiol Rev 81:117-151.

Frings S, Seifert R, Godde M, Kaupp UB (1995) Profoundly different calcium permeation and blockage determine the specific function of distinct cyclic nucleotide-gated channels. Neuron 15:169-179.

Gordon SE, Brautigan DL, Zimmerman AL (1992) Protein phosphatases modulate the apparent agonist affinity of the light-regulated ion channel in retinal rods. Neuron 9:739-748.

Hackos DH, Korenbrot JI (1997) Calcium modulation of ligand affinity in the cyclic GMP-gated ion channels of cone photoreceptors. J Gen Physiol 110:515-528.

Hasegawa M, Cahill GM (1999) A role for cyclic AMP in entrainment of the circadian oscillator in Xenopus retinal photoreceptors by dopamine but not by light. J Neurochem 72:1812-1820.

Hillman DW, Lin D, Burnside B (1995) Evidence for D4 receptor regulation of retinomotor movement in isolated teleost cone inner-outer segments. J Neurochem 64:1326-1335.

Huff RM (1996) Signal transduction pathways modulated by the D2 subfamily of dopamine receptors. Cell Signal 8:453-459.

Hsu YT, Molday RS (1993) Modulation of the cGMP-gated channel of rod photoreceptor cells by calmodulin. Nature 361:76-79.

Ignatova EG, Belcheva MM, Bohn LM, Neuman MC, Coscia CJ (1999) Requirement of receptor internalization for opioid stimulation of mitogenactivated protein kinase: biochemical and immunofluorescence confocal microscopic evidence. J Neurosci 19:56-63.

Iuvone PM (1986) Evidence for a D2 dopamine receptor in frog retina that decreases cyclic AMP accumulation and serotonin $\mathrm{N}$-acetyltransferase activity. Life Sci 38:331-342.

Iuvone PM, Avendano G, Butler BJ, Adler R (1990) Cyclic AMP-dependent induction of serotonin $\mathrm{N}$-acetyltransferase activity in photoreceptorenriched chick retinal cell cultures: characterization and inhibition by dopamine. J Neurochem 55:673-682.

Ko GY, Ko ML, Dryer SE (2001) Circadian regulation of cGMP-gated cationic channels of chick retinal cones. Erk MAP Kinase and $\mathrm{Ca}^{2+}$ / calmodulin-dependent protein kinase II. Neuron 29:255-266.

Kosolapov AV, Bobkov YV (1996) Modulation of the cGMP-activated conductance of the plasma membrane of photoreceptor cells by calmodulin. Biochem Mol Biol Int 38:871-877.

Kramer RH, Molokanova E (2001) Modulation of cyclic-nucleotide-gated channels and regulation of vertebrate phototransduction. J Exp Biol 204:2921-2931.

Krizaj D (2000) Mesopic state: cellular mechanisms involved in pre- and post-synaptic mixing of rod and cone signals. Microsc Res Tech 50:347-359.

Luo Y, Kokkonen GC, Wang X, Neve KA, Roth GS (1998) D2 dopamine receptors stimulate mitogenesis through pertussis toxin-sensitive $\mathrm{G}$ proteins and Ras-involved ERK and SAP/JNK pathways in rat C6-D2L glioma cells. J Neurochem 71:980-990.

Manglapus MK, Uchiyama H, Buelow NF, Barlow RB (1998) Circadian rhythms of rod-cone dominance in the Japanese quail retina. J Neurosci 18:4775-4784.

Manglapus MK, Iuvone PM, Underwood H, Pierce ME, Barlow RB (1999) Dopamine mediates circadian rhythms of rod-cone dominance in the Japanese quail retina. J Neurosci 19:4132-4141.

Maudsley S, Pierce KL, Zamah AM, Miller WE, Ahn S, Daaka Y, Lefkowitz RJ, Luttrell LM (2000) The $\beta_{2}$-adrenergic receptor mediates extracellular signal-regulated kinase activation via assembly of a multi-receptor complex with the epidermal growth factor receptor. J Biol Chem 275:9572-9580

Miller JL, Korenbrot JI (1993) In retinal cones membrane depolarization in darkness activates the cGMP-dependent conductance: a model for Ca homeostasis and the regulation of guanylate cyclase. J Gen Physiol 101:933-960.

Molokanova E, Trivedi B, Savchenko A, Kramer RH (1997) Modulation of rod photoreceptor cyclic nucleotide-gated channels by tyrosine phosphorylation. J Neurosci 17:9068-9076.

Molokanova E, Maddox F, Luetje CW, Kramer RH (1999) Activitydependent modulation of rod photoreceptor cyclic nucleotide-gated channels mediated by phosphorylation of a specific tyrosine residue. J Neurosci 19:4786-4795.

Nowak JZ, Kazula A, Golembiowska K (1992) Melatonin increases serotonin $N$-acetyltransferase activity and decreases dopamine synthesis in light-exposed chick retina: in vivo evidence supporting melatonindopamine interaction in retina. J Neurochem 59:1499-1505.

Oak JN, Lavine N, Van Tol HH (2001) Dopamine D4 and D2L receptor stimulation of the mitogen-activated protein kinase pathway is dependent on trans-activation of the platelet-derived growth factor receptor. Mol Pharmacol 60:92-103. 
Okano T, Yamamoto K, Okano K, Hirota T, Kasahara T, Sasaki M, Takanaka Y, Fukada Y (2001) Chicken pineal clock genes: implication of BMAL2 as a bi-directional regulator in circadian clock oscillation. Genes Cells 6:825-836.

Picones A, Korenbrot JI (1992) Permeation and interaction of monovalent cations with the cGMP-gated channel of cone photoreceptors. J Gen Physiol 100:647-673.

Pierce ME, Sheshberadaran H, Zhang Z, Fox LE, Applebury ML, Takahashi JS (1993) Circadian regulation of iodopsin gene expression in embryonic photoreceptors in retinal cell culture. Neuron 10:579-584.

Pierce KL, Maudsley S, Daaka Y, Luttrell LM, Lefkowitz RJ (2000) Role of endocytosis in the activation of the extracellular signal-regulated kinase cascade by sequestering and nonsequestering $\mathrm{G}$ protein-coupled receptors. Proc Natl Acad Sci USA 97:1489-1494.

Rebrik TI, Korenbrot JI (1998) In intact cone photoreceptors, a $\mathrm{Ca}^{2+}$ dependent, diffusible factor modulates the cGMP-gated ion channels differently than in rods. J Gen Physiol 112:537-548.

Rebrik TI, Kotelnikova EA, Korenbrot JI (2000) Time course and $\mathrm{Ca}^{2+} \mathrm{de}-$ pendence of sensitivity modulation in cyclic GMP-gated currents of intact cone photoreceptors. J Gen Physiol 116:521-534.

Ribelayga C, Wang Y, Mangel SC (2002) Dopamine mediates circadian clock regulation of rod and cone input to fish retinal horizontal cells. J Physiol (Lond) 544:801-816.

Rieke F, Schwartz EA (1994) A cGMP-gated current can control exocytosis at cone synapses. Neuron 13:863-873.

Roenneberg T, Merrow M (1999) Circadian systems and metabolism. J Biol Rhythms 14:449-459.
Savchenko A, Barnes S, Kramer RH (1997) Cyclic-nucleotide-gated channels mediate synaptic feedback by nitric oxide. Nature 390:694-698.

Shearman LP, Sriram S, Weaver DR, Maywood ES, Chaves I, Zheng B, Kume K, Lee CC, van der Horst GT, Hastings MH, Reppert SM (2000) Interacting molecular loops in the mammalian circadian clock. Science 288:1013-1019.

Steenhard BM, Besharse JC (2000) Phase shifting the retinal circadian clock: xPer2 mRNA induction by light and dopamine. J Neurosci 20:8572-8577.

Stenkamp DL, Iuvone PM, Adler R (1994) Photomechanical movements of cultured embryonic photoreceptors: regulation by exogenous neuromodulators and by a regulable source of endogenous dopamine. J Neurosci 14:3083-3096.

Wagner HJ, Luo BG, Ariano MS, Sibley DR, Stell WK (1993) Localization of D2 dopamine receptors in vertebrate retinae with anti-peptide antibodies. J Comp Neurol 331:469-481.

Wang Y, Mangel SC (1996) A circadian clock regulates rod and cone input to fish retinal cone horizontal cells. Proc Natl Acad Sci USA 93:4655-4660.

Witkovsky P, Stone S, Besharse JC (1988) Dopamine modifies the balance of rod and cone inputs to horizontal cells of the Xenopus retina. Brain Res 449:332-336.

Yan Z, Feng J, Fienberg AA, Greengard P (1999) D2 dopamine receptors induce mitogen-activated protein kinase and cAMP response elementbinding protein phosphorylation in neurons. Proc Natl Acad Sci USA 96:11607-11612. 